\title{
Synthesis of ethylolammonium salts of diethylolamido phosphate surfactant based on the flaxseed oil and their corrosion inhibitor properties
}

\author{
V.M.Abbasov, Z.H.Asadov, S.S.Suleymanova, R.A.Rahimov, E.Sh.Abdullayev \\ Institute of Petrochemical Processes of Azerbaijan National Academy of Sciences, \\ Hojaly ave. 30, Az 1025, Baku, Azerbaijan
}

\section{ABSTRACT}

revan_chem@mail.ru

Diethylolamide of flaxseed oil has been synthesized and modified with H3PO4. The obtained compound was neutralized by monoethanolamine, diethanolamine and triethanolamine. The progress of the reactions was monitored and confirmed by FTIR, 1H NMR and 13C NMR. The physical properties of the synthesized surfactants were studied. The surface properties such as the critical micelle concentration $(\mathrm{CMC})$, the effectiveness of surface tension reduction (ПСМС), surface excess concentration (Гmax) and surface area per molecule (Amin) have been determined by means of interface tension measurements. They were tested as corrosion inhibitors for carbon steel in H2S medium. It was found that the corrosion inhibition efficiency depends on both concentration and molecular structure of the inhibitors.

\section{Indexing terms/Keywords}

Surfactants; Surface properties; Adsorption; Corrosion inhibitors; H2S environment

\section{Academic Discipline And Sub-Disciplines}

Chemistry

\section{SUBJECT CLASSIFICATION}

Petroleum Chemistry

\section{TYPE (METHOD/APPROACH)}

Experimental

\section{Council for Innovative Research}

Peer Review Research Publishing System

\section{Journal: Journal of Advances in Chemistry}

Vol. 12, No. 1

www.cirjac.com

editorjaconline@gmail.com, editor@cirjac.com 


\section{INTRODUCTION}

Carbon steel as a relatively cheap material having very high mechanical characteristics is widely used in practically all fields. Regrettably, this alloy undergoes corrosion in practice under the action of such aggressive components as hydrochloric and hydrosulphuric acids, carbon dioxide and many others [1]. Hydrochloric acid is very effective for dissolving calcium carbonate scale inside the pipelines and finds a large application with this goal. There are several ways for decreasing the rate of metals corrosion. One of them is an introduction of inhibitors into acidic systems. The most preferable inhibitors for protection of metals against corrosion are of organic nature and contain such heteroatoms as nitrogen, oxygen, phosphorus and sulphur as well as aromatic rings and multiple bonds. Among various groups of inhibitors surface-active inhibitors are characterized by high levels of inhibition efficiency, cheapness, relative harmlessness and easiness of production. Inhibition was reported to be realized as a result of adsorption of the surfactant molecules, with an aid of their functional groups, to the metal surface [2-5].

Presence of such heteroatoms as nitrogen, sulfur and oxygen, because of their tendency to be adsorbed at the $\mathrm{metal} /$ media interface with formation of protective layer, is very important [6-8]. effects [9].

Inhibition of iron corrosion by surfactants may occur via two phenomena consisting in blocking and hydrophobing

As is known, inhibitors are considered to be optimal if they are based on relatively cheap and non-toxic initial components and contain the above-shown heteroatoms and fragments. From this standpoint vegetable oils are very convenient raw materials as they are restorable and ecologically clean [10-13].

In the present study weight loss measurements were performed to examine the H2S acid corrosion inhibition process of carbon steel by some surfactants synthesized on the basis of flaxseed oil and such ethanolamines as monoethanolamine (MEA), diethanolamine (DEA) and triethanolamine (TEA) for the range of concentrations below the critical micelle concentration. Similar surfactants were synthesized and studied as chemicals for removing thin petroleum films from water surface [14]. Meanwhile, the values of interfacial tension at the water-kerosene border in the presence of the synthesized surfactants have been determined and respective colloidal-chemical parameters have been computed.

\section{EXPERIMENTAL PROCEDURES}

\subsection{INSTRUMENTS AND MATERIALS}

1H NMR and 13C NMR spectra were recorded on Bruker Avance II+300 (UltraShield ${ }^{\mathrm{TM}}$ Magnet) $300.13 \mathrm{MHz}$ and $75.46 \mathrm{MHz}$ spectrometer using $\mathrm{CCl} 3 \mathrm{D}$ as solvents. Infrared spectra $(4000-400 \mathrm{~cm}-1)$ were recorded on a Vertex 70 (Bruker) instrument in $\mathrm{KBr}$ pellets.

Flaxseed oil was obtained from Schneekoppe GmbH \& Co, Germany. MEA (purity > 99\% Merck®, Germany), DEA (purity > 98.5\% Merck®, Germany) and TEA (purity > 99\% Merck®, Germany) were of analytical grade. Orthophosphoric acid (85\% wt. solution) was from Moscow's "Component-Reactant" Joint Stock Company (Russia) production. Kerosene was purified from aromatic compounds by treatment with sulfuric acid up to a surface tension of $24 \mathrm{mN} / \mathrm{m}(20$ $\left.{ }^{\circ} \mathrm{C}\right)$.

\subsection{Synthesis of diethylolamide}

The reaction was carried out in a round bottom Pyrex glass reaction flask submerged in an oil bath. The reaction flask was equipped with a mechanical stirrer, thermometer and condenser. DEA was reacted with the flaxseed oil at a molar ratio of 3:1. The reaction was carried out at a temperature of $145-155{ }^{\circ} \mathrm{C}$ and the formation of the diethylolamide was monitored with FTIR. At the end of the reaction, the reaction mixture was allowed to cool and was later dissolved in diethyl ether in a separating funnel. The ether phase was washed with $5 \%$ aqueous hydrochloric acid. The ether layer was separated, washed with water and passed over sodium sulphate. The resulting ether layer was later concentrated using a rotary evaporator.

\subsection{Synthesis of ethylolammonium salts of ethylolamide phosphate}

Ortho-phosphoric acid $(0.135 \mathrm{~mol})$ was added to $400 \mathrm{~mL}$ of anhydrous benzene at $50{ }^{\circ} \mathrm{C}$ in a three-necked round-bottom flask equipped with a thermometer sensor and a magnetic stirrer. The diethylolamide $(0.135$ mol) was gradually introduced into the flask and allowed to react with the phosphoric acid until a complete conversion was achieved. About $250 \mathrm{~mL}$ of deionized water was poured into the reaction mixture and left for $3 \mathrm{~h}$. The organic phase was extracted three times with diethyl ether, washed with $\mathrm{HCl}(1 \mathrm{~mol} \mathrm{dm}-3)$ and deionized water until free of acid. The diethyl ether was evaporated under reduced pressure, and then poured in ethanolic solution of the respective ethanolamine ( $0.135 \mathrm{~mol})$. The resulting ethanol layer was later concentrated using a rotary evaporator at a reduced pressure to give a brown liquid which was finally air dried. 
Ethylolamide phosphate-IR vmax (cm-1): $1098(\mathrm{P}-\mathrm{O}), 1655(\mathrm{C}=\mathrm{O}), 2927(\mathrm{C}-\mathrm{H}), 3442(\mathrm{O}-\mathrm{H})$. 1H-NMR $(300.13$ $\mathrm{MHz}, \mathrm{CCl} 3 \mathrm{D}$ ), $\delta$ (ppm): 0.85-0.88 (CH3), 0.94-0.99 (CH3), 1.11-1.31 (CH2 chain), 1.60-1.64 (CH2-CH2-C(O)), 1.99-2.30 $(\mathrm{CH} 2-\mathrm{CH}=\mathrm{CH}), 2.74-2.81(\mathrm{CH}=\mathrm{CH}-\mathrm{CH} 2-\mathrm{CH}=\mathrm{CH}), 3.58-3.68(\mathrm{~N}-\mathrm{CH} 2-\mathrm{CH} 2-\mathrm{OH}), 3.8-4.1 \quad(\mathrm{NH}-\mathrm{CH} 2-\mathrm{CH} 2-\mathrm{O}-\mathrm{P}), 5.2-5.4$ $(\mathrm{CH}=\mathrm{CH}), 7.7(\mathrm{P}-\mathrm{OH})$ (Fig 1). 13C-NMR (75.46 MHz, CCl3D), $\delta(\mathrm{ppm}):$ 14.2-14.4 (CH3), 20.7-34.2 (CH2 chain), 61.7-77.4 $(\mathrm{N}-\mathrm{CH} 2-\mathrm{CH} 2-\mathrm{OH}$ and $\mathrm{N}-\mathrm{CH} 2-\mathrm{CH} 2-\mathrm{O}-\mathrm{P}), 127.2-132.0(\mathrm{CH}=\mathrm{CH}), 173.9-179.9 \mathrm{C}(\mathrm{O}) \mathrm{N}$.

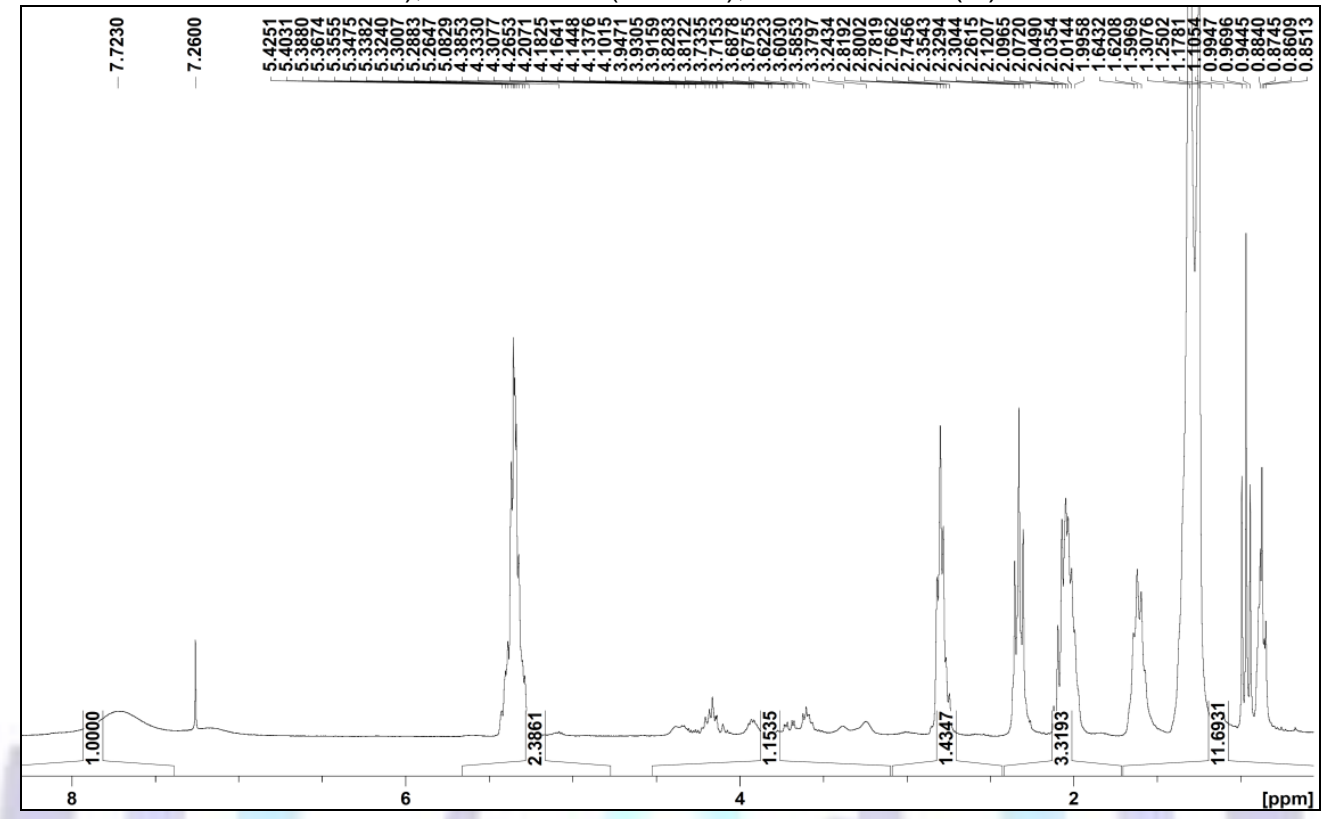

Fig 1. 1H-NMR spectrum of flaxseed oil ethylolamide phosphate

Monoethylolammonium salt of ethylolamide phosphate -IR vmax $(\mathrm{cm}-1)$ : $1067(\mathrm{P}-\mathrm{O}), 1654(\mathrm{C}=\mathrm{O}), 2364(\mathrm{~N}+\mathrm{H})$ $2927(\mathrm{C}-\mathrm{H}), 3448(\mathrm{O}-\mathrm{H}) .1 \mathrm{H}-\mathrm{NMR}(300.13 \mathrm{MHz}, \mathrm{CCl} 3 \mathrm{D}), \delta(\mathrm{ppm}): 0.87-0.99(\mathrm{CH} 3), 1.24-1.30(\mathrm{CH} 2 \mathrm{chain}), 1.59-1.61$ $(\mathrm{CH} 2-\mathrm{CH} 2-\mathrm{C}(\mathrm{O})), 1.99-2.34(\mathrm{CH} 2-\mathrm{CH}=\mathrm{CH}), 2.76-2.81(\mathrm{CH}=\mathrm{CH}-\mathrm{CH} 2-\mathrm{CH}=\mathrm{CH}), 3.58-3.62(\mathrm{~N}-\mathrm{CH} 2-\mathrm{CH} 2-\mathrm{OH}), 4.14-4.20$ ( $\mathrm{NH}-\mathrm{CH} 2-\mathrm{CH} 2-\mathrm{O}-\mathrm{P}), 5.28-5.40(\mathrm{CH}=\mathrm{CH})$ (Fig 2). 13C-NMR (75.46 MHz, CCl3D), ठ (ppm): 14.2-14.4 (CH3), 20.7-34.4 ( $\mathrm{CH} 2$ chain), 61.7-77.4 (N-CH2- $\mathrm{CH} 2-\mathrm{OH}$ and $\mathrm{N}-\mathrm{CH} 2-\mathrm{CH} 2-\mathrm{O}-\mathrm{P}), 127.2-132.0(\mathrm{CH}=\mathrm{CH}), 173.6-179.6 \mathrm{C}(\mathrm{O}) \mathrm{N}$.

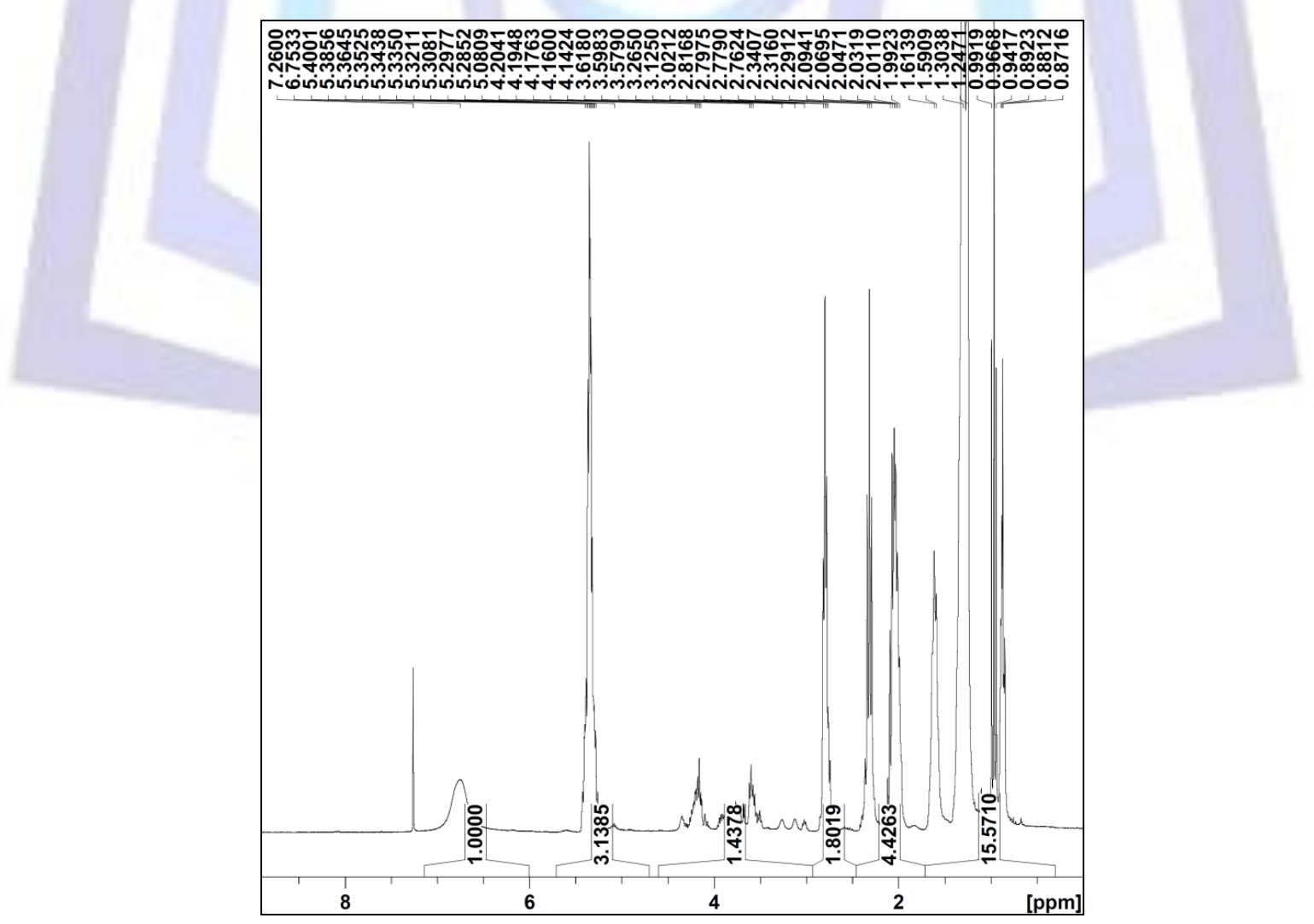

Fig 2. 1H-NMR spectrum of monoethylolammonium salt of flaxseed oil ethylolamide phosphate 


\subsection{Interfacial tension measurements}

All the interfacial tension measurements [15] were carried out using kerosene to make the solutions. The solutions kept at the desired temperature were measured $60 \mathrm{~s}$ after transfer to the thermostated measuring dishes. The actual temperature within the dishes was controlled prior to and after the measurement by means of a thermocouple. Deviations from the desired temperature were $\pm 0.2^{\circ} \mathrm{C}$. The interfacial tension as a function of concentration was measured at $20^{\circ} \mathrm{C}$ using a drop volume Traube stalagmometer (Russian Federation). Interfacial tension values from the two measurements varying by no more than $0.2 \mathrm{mN} \mathrm{m}-1$ were averaged and reported. The interfacial tension of pure kerosene at the border with water was $46.5 \mathrm{mN} \mathrm{m}-1$.

\subsection{Weight Loss Measurements}

The weight loss experiments were performed with carbon steel specimens having a composition of (wt\%): 0.21 $0,22 \mathrm{C}, 0,15-0,30 \mathrm{Si}, 0.40-0.65 \mathrm{Mn},<0,30 \mathrm{Ni},<0,05 \mathrm{~S},<0,04 \mathrm{P},<0,3 \mathrm{Cr},<0,008 \mathrm{~N},<0,3 \mathrm{Cu},<0,08 \mathrm{As}$ and the remainder $\mathrm{Fe}$.

The carbon steel sheets of $2 \times 4 \times 0.4 \mathrm{~cm}$ were abraded with a series of emery papers (grade 320, 500, 800 and $1,200)$ and then washed with acetone and distilled water. After weighing accurately, the specimens were immersed in a closed flask contained $250 \mathrm{~mL}$ of a solution of hydrosulfuric acid without and with the tested inhibitors I, II and III at different concentrations $\left(10,20,50\right.$ and $100 \mathrm{ppm}$ by weight) for $5 \mathrm{~h}$ at $20^{\circ} \mathrm{C}$. Then, the specimens were taken out, washed, dried and weighed accurately. The test was performed for three specimens and the weight was the average of the three specimens. The coupons were polished with a hard plastic brush, first with hot water, then with ethanol to remove the corrosion products. The corrosion rate $(R)$, the inhibition efficiency (IE \%) and degree of surface coverage $(\theta)$ were calculated using Eqs. (1-3) [11,12]:

$$
\begin{aligned}
& R=W / A \cdot \tau \\
& I E \%=\left[\left(R_{0}-R\right) / R_{0}\right] \times 100 \\
& \theta=1-\left(R / R_{0}\right)
\end{aligned}
$$

where $\mathrm{W}$ is the average weight loss of three parallel carbon steel sheets, $\mathrm{A}$ is the total surface area of the specimen, $\tau$ is immersion time, $\mathrm{R} 0$ and $\mathrm{R}$ are the values of the corrosion rate without and with addition of the inhibitor, respectively.

\section{Results and Discussion}

\subsection{Synthesis of ethylolammonium salts}

The reaction was carried out using flaxseed oil as the starting material. The oil was reacted with DEA at molar ratio of 1:3 (flaxseed oil:DEA) (Scheme 1):<smiles>[R]C(=O)OC(=O)COCCCNCCOCCNC(=O)OCCO</smiles>

Glycerol was produced as the by-product of the reaction.

The synthesized diethylolamide was modified with ortho-phosphoric acid at the molar ratio 1:1. The reaction equation is shown in Scheme 2:<smiles></smiles>

The obtained phosphate derivative was neutralized with MEA, DEA and TEA. The scheme of the neutralization reaction is as following: 


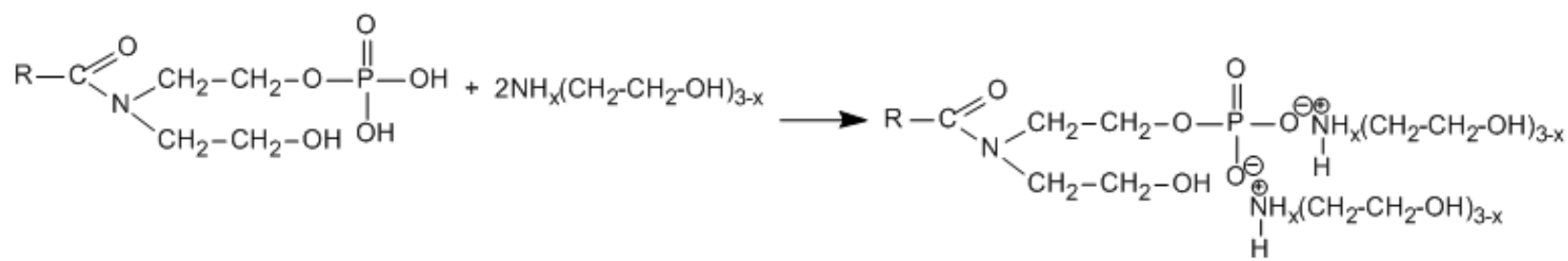

where $\mathrm{x}=0,1$ or 2 .

\subsection{Surface activity of the synthesized surfactants}

The critical micelle concentrations (CMC) were determined by the surface balance method. The CMC values of the prepared ethylolammonium salts were determined at $293 \mathrm{~K}$ from the change in the slope of the plotted data of interfacial tension versus the natural logarithm of the solute concentration. Some representative plots (Fig. 3) were illustrated here for brevity. The obtained values of CMC for surfactants at $293 \mathrm{~K}$ temperature are tabulated in Table 1 , together with values for the interfacial tension at CMC. Generally, the increasing in the number of ethylol groups in the head group of molecule decreases CMC values due to decreasing the solubility of the surfactants in kerosene. Such improved water-solubility lowers the tendency for the surfactant to form micelles.

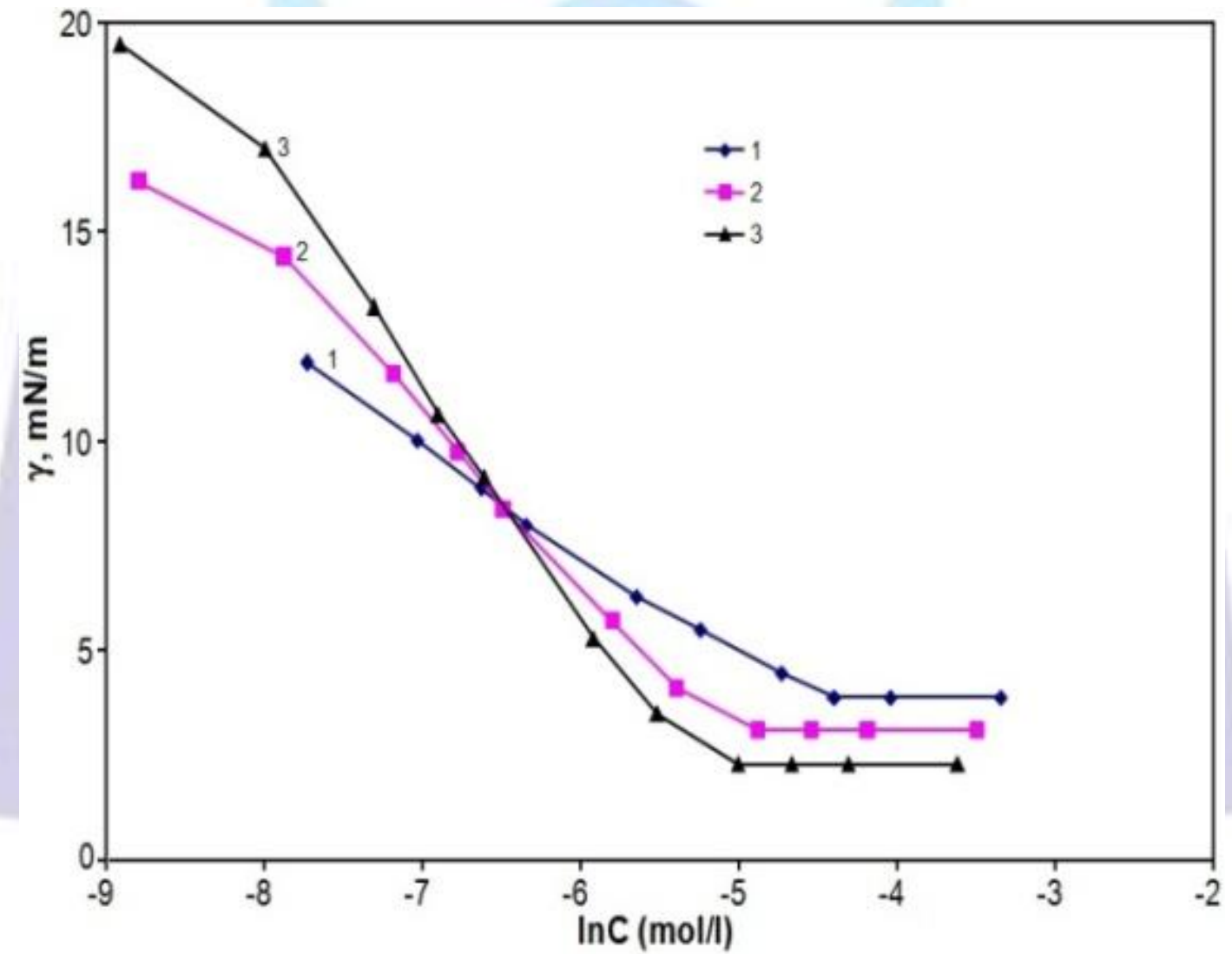

Fig 3. Interfacial tension at the border kerosene-water vs. In of the concentration of surfactants in kerosene solution (1-MEA salt, 2-DEA salt, 3-TEA salt) $\left(20^{\circ} \mathrm{C}\right)$

Table 1. Interface properties of the ethylolammonium salts of diethylolamide phosphate surfactant based on flaxseed oil; $293 \mathrm{~K}$ temperature ${ }^{\mathrm{a}}$

\begin{tabular}{|c|c|c|r|r|r|r|r|}
\hline Surfactants & $\begin{array}{c}\mathrm{CMC} \times 10^{3}, \\
\mathrm{~mol} \cdot \mathrm{dm}^{-3}\end{array}$ & $\begin{array}{c}\gamma_{\mathrm{CMC}}, \\
\mathrm{mN} \cdot \mathrm{m}^{-1}\end{array}$ & $\begin{array}{r}\Gamma_{\max } \times 10^{10} \\
\mathrm{~mol} \cdot \mathrm{cm}^{-2}\end{array}$ & $\begin{array}{c}\mathrm{A}_{\mathrm{min}} \times 10^{2}, \\
\mathrm{~nm}^{2}\end{array}$ & $\begin{array}{c}\pi_{\mathrm{CMC}}, \\
\mathrm{mN} \cdot \mathrm{m}^{-1}\end{array}$ & $\begin{array}{c}\Delta \mathrm{G}_{\mathrm{mic}}, \\
\mathrm{kJ} \cdot \mathrm{mol}^{-1}\end{array}$ & $\begin{array}{c}\Delta \mathrm{G}_{\mathrm{ad}}, \\
\mathrm{kJ} \cdot \mathrm{mol}^{-1}\end{array}$ \\
\hline MEA salt & 12.3 & 3.9 & 0.49 & 336.1 & 42.6 & -10.7 & -19.3 \\
\hline DEA salt & 7.5 & 3.1 & 0.86 & 193.8 & 43.4 & -11.9 & -17.0 \\
\hline TEA salt & 6.7 & 2.3 & 1.13 & 147.2 & 44.2 & -12.2 & -16.1 \\
\hline
\end{tabular}


${ }^{\mathrm{a}} \mathrm{CMC}$, critical micelle concentration; ${ }^{\gamma} \mathrm{CMC}$, equilibrium interface tension at the $\mathrm{CMC}$; $\Gamma \mathrm{max}$, the maximum surface excess concentration at the kerosene solution/water interface; Amin, the minimum area per surfactant molecule at kerosene solution/water interface; ${ }^{\pi} \mathrm{CMC}$, effectiveness of interface tension reduction; $\Delta \mathrm{Gmic}$, change of standard free energy of micellization; $\Delta \mathrm{Gad}$, change of standard free energy of adsorption.

As a result, a plot of interfacial tension as a function of equilibrium concentration of surfactant in one of the liquid phases, rather than an adsorption isotherm, is generally used to describe adsorption at this interface. The concentration of surfactant at the interface may therefore be calculated from interfacial tension data by using the following equation [16]:

$$
\Gamma=-\frac{1}{R T}\left(\frac{\partial \gamma}{\partial \ln C}\right)_{T}
$$

where $\left(\frac{\partial \gamma}{\partial \ln C}\right)_{T}$

is the slope of the plot of $\gamma$ versus InC at a constant temperature $(T)$, and $R$ is the gas constant in $\mathrm{J} \cdot \mathrm{mol}-1 \cdot \mathrm{K}-1$. The surface excess concentration at surface saturation ( $\Gamma \max )$ can be readily found and it is a useful measure of the effectiveness of adsorption of surfactant at the liquid-gas or liquid-liquid interface, since it is the maximum value to which adsorption can attain.

From the surface excess concentration, the area per molecule at interface is calculated using Equation (2)

$$
\mathrm{A}_{\text {min }}=\frac{10^{16}}{N \Gamma_{\max }}
$$

where $\mathrm{N}$ is Avogadro's number.

The effectiveness of interfacial tension reduction, $\pi \mathrm{CMC}=\gamma 0-\gamma \mathrm{CMC}$, where $\gamma 0$ is the interfacial tension at the kerosene/water border and $\gamma \mathrm{CMC}$ is the interfacial tension at the kerosene solution of surfactant/water border at CMC, was determined at $293 \mathrm{~K}$ temperature. The $\Gamma \max$, Amin and $\gamma \mathrm{CMC}$ values were calculated and listed in Table 1 . The data listed in Table 1 show that the minimum areas per molecule at the kerosene solution/water interface decrease with the increase of the number of ethylol units in the head group molecule. The data on Amin and $\Gamma$ max indicate the dependence of the effectiveness of adsorption at the kerosene solution/water interface from the structure of surfactants. It was found that increase in the number of hydroxyethylol groups in surfactant structure appears to have an unusual decrease in Amin at the interface. This can be attributed to the fact that TEA has a branched hydroxyethyl group, which makes coiling of hydrophobic chain with a consequent decrease in Amin [17].

The effectiveness of interfacial tension reduction in these compounds shows a steady rise with increase in the number of ethylol groups.

\subsection{Standard free energies of micellization and adsorption at the kerosene solution/water}

\section{interface}

Standard free energies of micellization $\Delta$ Gmic, for the synthesized surfactants have been calculated by equation[16]

$\Delta \mathrm{Gmic}=\mathrm{RT} \operatorname{InCMC} \quad(3)$ relationship[6]

Standard free energies of adsorption $\Delta \mathrm{Gad}$ for these surfactants have been determined by using the

$$
\triangle \mathrm{Gad}=\mathrm{RT} \text { InCMC }-\pi \mathrm{CMCACMC} \quad \text { (4) }
$$

The found values of $\Delta \mathrm{Gmic}$ and $\Delta \mathrm{Gad}$ are listed in Table 1. From these data it may be concluded that micellization process has a spontaneous character $(\Delta \mathrm{Gmic}<0)$. All values found for $\Delta \mathrm{Gad}$ are negative. Moreover, they are more negative than those of $\Delta \mathrm{Gmic}$, i.e. adsorption of the mentioned surfactants at the kerosene/water interface is associated with a larger decrease in free energy of the system. As the number of ethylol groups of head group rises, the values of $\Delta$ Gmic decrease, while the values of $\Delta$ Gad increase. This indicates that the increase in the number of ethylol groups at $\mathrm{N}$ atom in these surfactants inhibit adsorption at the kerosene solution/water interface.

\subsection{Effect of inhibitor concentration}

It can be seen that the presence of inhibitors results in a high decrease in the rate of corrosion. In the case of these inhibitors, the corrosion rate decreases as the inhibitor concentration increases, getting maximum inhibition efficiency ranged between 97.0 and $99.5 \%$ at 100 ppm after 5 hours of exposure (Table 2). This trend may result from the fact that adsorption of these complex surfactants forms thin inhibitor films on the metal surface which relatively isolate the metal surface from the corrosive environment causing much reduced corrosion rates. Inhibition efficiency of these films depends on various factors including but not limited to corrosiveness of the environment, concentration of the surfactant, any synergetic effects with other molecules present in the environment and/or flow/ shear effects. 
Table 2. Corrosion rate, degree of surface coverage and inhibitor efficiency at different concentrations of surfactants in H2S solution at $293 \mathrm{~K}$ (according to weight loss measurements)

\begin{tabular}{|c|c|c|c|c|}
\hline Inhibitors & $\begin{array}{l}\text { Concentration } \\
(\mathrm{ppm})\end{array}$ & $\begin{array}{l}\text { Rate of } \\
\text { corrosion, } \\
\mathrm{g} /\left(\mathrm{m}^{2} \cdot \text { hour }\right)\end{array}$ & $\begin{array}{l}\text { Surface } \\
\text { coverage, } \theta\end{array}$ & $\begin{array}{l}\text { The inhibition } \\
\text { efficiency, IE\% }\end{array}$ \\
\hline Blank & - & 2.9 & - & - \\
\hline MEA salt & 10 & 1.10 & 0.620 & 62.0 \\
& 20 & 0.46 & 0.840 & 84.0 \\
& 50 & 0.05 & 0.980 & 98.0 \\
& 100 & 0.01 & 0.995 & 99.5 \\
\hline DEA salt & 10 & 1.01 & 0.650 & 65.0 \\
& 20 & 0.69 & 0.760 & 76.0 \\
& 50 & 0.14 & 0.950 & 95.0 \\
& 100 & 0.08 & 0.970 & 97.0 \\
\hline TEA salt & 10 & 1.01 & 0.650 & 65.0 \\
& 20 & 0.46 & 0.840 & 84.0 \\
& 50 & 0.14 & 0.950 & 95.0 \\
& 100 & 0.04 & 0.983 & 98.3 \\
\hline
\end{tabular}

\subsection{Adsorption isotherm and thermodynamic considerations}

The adsorption isotherms can provide basic information on the interaction of inhibitor and metal surface. In order to obtain adsorption isotherm, the surface coverage values $(\theta)$ for different concentrations of the prepared surfactants in H2S solution have been obtained from gravimetric measurements and tested graphically for fitting a suitable adsorption isotherm. The plot of $\mathrm{C} / \theta$ versus $\mathrm{C}$ gave a straight line with correlation coefficient of 0.9998 and the slope closed to 1 providing that the adsorption of the prepared surfactants in solution of hydrosulfuric acid on the carbon steel surface obeys Langmuir adsorption isotherm, which is presented by Eq. (5).

$$
\frac{C}{\theta}=\frac{1}{K_{a d s}}+C
$$

where $\mathrm{C}$ is the inhibitor concentration, $\theta$ is the degree of coverage on the metal surface and Kads is the equilibrium constant for adsorption-desorption process (Table 3$)$. The high values of the adsorption equilibrium constant $(1.36 \times 105$, $1.18 \times 105$ and $1.34 \times 105 \mathrm{M}-1$ for MEA, DEA and TEA, respectively, at $20{ }^{\circ} \mathrm{C}$ ) reflect the high adsorption ability of this inhibitor on carbon steel surface. The free energy of adsorption of inhibitor on carbon steel surface can be evaluated with the following equation:

$$
\Delta G_{a d s}=-R T \ln \left(55.55 K_{a d s}\right)
$$

where $\Delta$ Gads is the free energy of adsorption of inhibitor molecules on metal surface, Kads is the equilibrium constant for adsorption-desorption process, $\mathrm{R}$ is the gas constant, $\mathrm{T}$ is the absolute temperature and 55.55 is the molar concentration of water.

Table 3. Thermodynamic parameters for the adsorption of the studied surfactants on carbon steel in H2S solution medium

\begin{tabular}{|l|c|c|c|l|}
\hline Inhibitor & Slope & $\begin{array}{l}\text { Regression } \\
\text { coefficient, } \mathrm{R}^{2}\end{array}$ & $\begin{array}{l}\mathrm{K}_{\mathrm{ads}} \times 10^{-5}, \\
\mathrm{M}^{-1}\end{array}$ & $\begin{array}{l}\Delta \mathrm{G}_{\mathrm{ads}}, \\
\mathrm{kJ} \cdot \mathrm{mol}^{-1}\end{array}$ \\
\hline MEA salt & 0.963 & 0.9999 & 1.36 & -38.58 \\
\hline DEA salt & 0.971 & 0.9998 & 1.18 & -38.24 \\
\hline TEA salt & 0.960 & 0.9999 & 1.34 & -38.54 \\
\hline
\end{tabular}


The negative values of $\Delta$ Gads indicate that the inhibitors are spontaneously adsorbed on the carbon steel surface. It is generally accepted that in the cases of the values of $\Delta$ Gads up to $-20 \mathrm{~kJ} \cdot \mathrm{mol}-1$, the types of adsorption are regarded as physisorption, where the inhibition acts due to the electrostatic interaction between the charged molecules and the charged metal, while the values around $-40 \mathrm{~kJ} \cdot \mathrm{mol}-1$ or smaller, are seen as chemisorption, which is due to the charge sharing or a transfer from the inhibitor molecules to the metal surface to form a covalent bond. It is clear from Table 3 that the values of $\Delta$ Gads in our measurements range from -38.24 to $38.58 \mathrm{~kJ}$ mol -1 . These results indicate that the adsorption mechanism of surfactants on carbon steel in H2S saturated brine is typical chemisorption at the studied temperature.

\section{CONCLUSIONS}

1. Flaxseed oil-based diethylolamide phosphate and its surface-active ethylolammonium salts have been synthesized. Their colloidal-chemical properties have been studied.

2. The investigated surfactants act as effective corrosion inhibitors for carbon steel in oil well formation water under H2S environment.

3. The adsorption of the synthesized surfactants molecules on the metal surface obeys Langmuir adsorption isotherm. The values of adsorption equilibrium constant suggest that the synthesized surfactants are strongly adsorbed on the carbon steel surface.

\section{REFERENCES}

[1]. Migahed M.A.; Abd-El-Raouf M.; Al-Sabagh A.M.; Abd-El-Bary H.M. Electrochim. Acta, 2005, 50, 4683.

[2]. Malik M.A.; Hashim M.A.; Nabi F.; Al-Thabaiti Sh.A.; Khan Z. Int. J. Electrochem. Sci., 2011, 6, 1927.

[3]. Motamedi M.; Tehrani-Bagha A.R.; Mahdavian M. Corrosion Science, 2013, 70, 46.

[4]. Migahed M.A.; Al-Sabagh A.M. Chemical Engineering Communications, 2009, 196, 1054.

[5]. Sharma V.; Borse M.; Jauhari S.; Pai K.B.; Devi S. Tenside Surfactants Detergents: 2005, 42, 163.

[6]. Al-Sabagh A.M.; Abd-El-Bary H.M.; El-Ghazawy R.A.; Mishrif M.R.; Hussein B.M. Egyptian Journal of Petroleum, 2011, 20, 33.

[7]. Badawi A.M.; Hegazy M.A.; El-Sawy A.A.; Ahmed H.M.; Kamel W.M. Materials Chemistry and Physics, 2010, 124, 458.

[8]. Aiad I.A.; Tawfik S.M.; Shaban S.M.; Abd-Elaal A.A.; El-Shafie M. J. Surfact. Deterg., 2014, 17, 391.

[9]. Mahmoud S.S. J. Mater. Sci., 2007, 42, 989.

[10].Rivera-Grau L.M.; Casales M.; Regla I.; Ortega-Toledo D.M.; Ascencio-Gutierrez J.A.; Gonzalez-Rodriguez J.G.; Martinez-Gomez L. Int. J. Electrochem. Sci., 2012, 7, 12391.

[11].Abbasov V.M.; Abd El-Lateef H.M.; Aliyeva L.I.; Ismayilov I.T.; Qasimov E.E.; Mamedova M.N. Journal of the Korean Chemical Society, 2013, 57, 25.

[12].Abd El-Lateef H.M.; Abbasov V.M.; Aliyeva L.I.; Qasimov E.E.; Ismayilov I.T. Materials Chemistry and Physics, 2013, 142, 502.

[13].Abbasov V.M.; Ismayilov I.T.; Abd El-Lateef H.M.; Akhmadbeyova S.F. Eur. Chem. Bull., 2014, 3(5), 437.

[14].Asadov Z.H.; Rahimov R.A.; Salamova N.V. Journal of the American Oil Chemists' Society, 2012, 89, 505.

[15].Mollet C.; Touhami Y.; Hornof V. J. Colloid and Interface Sci., 1996, 178, 523.

[16]. Rosen M.J. Surfactants and interfacial phenomena. John Wiley and Sons Inc., 3rd Edn, New York, 2004.

[17].Asadov Z.H.; Rahimov R.A.; Nasibova Sh.M.; Ahmadova G.A. J. Surfact. Deterg., 2010, 13, 459. 